\title{
Correction to: The Relationship Between Identity Importance and Identity Salience: Context Matters
}

\author{
Peggy A. Thoits
}

Correction to:

Chapter "The Relationship Between Identity Importance and Identity Salience: Context Matters" in: R. T. Serpe et al. (eds.), Identity and Symbolic Interaction, https://doi.org/10.1007/978-3-030-41231-9_2

The original version of the book was inadvertently published with incorrect Table 4 in the chapter "The Relationship Between Identity Importance and Identity Salience: Context Matters", which has now been corrected. The book and the chapter have been updated with the change. 
Table 4 Respondents' replies to open-ended visitor salience questions, telephone subsample only $(\mathrm{N}=78)$

\begin{tabular}{l|l|l}
\hline & & $\%$ \\
\hline 8 & I am very likely to mention my visitor identity & 19.2 \\
\hline 7 & & $\%$ \\
\hline 6 & I am likely to mention my visitor identity if I'm asked what I do & 29.5 \\
\hline 5 & I am likely to mention my visitor identity if health topics come up & 5.1 \\
\hline 4 & I am unlikely to mention my visitor identity unless I'm asked what I do & 19.2 \\
\hline 3 & I am unlikely to mention my visitor identity unless health topics come up & 14.1 \\
\hline & & $\%$ \\
\hline 2 & I am unlikely to mention my visitor identity & 6.4 \\
\hline 1 & I am very unlikely to mention my visitor identity & 1.3 \\
\hline & & 100.0 \\
\hline
\end{tabular}

